\title{
Proceeding
}

9th INSHS International Christmas Sport Scientific Conference, 4-6 December 2014. International Network of Sport and Health

Science. Szombathely, Hungary

\section{Optimization of a jump shot rhythm at the junior level of basketball performance}

\author{
BORIS BAZANOV ,INDREK RANNAMA, KERSTI SIREL \\ Institute of Health Sciences and Sports, Tallinn University, Estonia
}

\begin{abstract}
Bazanov, B., Rannama, I., \& Sirel, K. (2015). Optimization of a jump shot rhythm at the junior level of basketball performance. J. Hum. Sport Exerc., 9(Proc1), pp.S176-S180. The jump shot is one of the most frequently used methods of shooting in the modern basketball. For example in the Spanish league, it accounts for $41 \%$ of all points (Rojas et al., 2000). Based on the results of our previous research which enabled to determine the phase structure and create rhythm models of shooting in elite male basketball (Bazanov, 2001, 2014) the purpose of this study was to improve the shooting rhythm of jump shot performances of male under 20 years old basketball players. The subjects used consisted of five under 20 years old basketball players of the Tallinn Basketball Academy. The whole action of shooting was divided into 5 phases and examined quantitatively and qualitatively. The data obtained were analyzed using descriptive statistics. The reliability of the differences was controlled by F-test and T-test. Results show, that the main changes occurred in preparation ("catching" and "sitting down") phases. We can conclude, that execution of technical requirements allows to change significantly the jump shot rhythm performance and reduce the duration of the jump shot in basketball. Key words: BASKETBALL, KINEMATIC ANALYSIS, TECHNIQUE, TEACHING.
\end{abstract}

Corresponding author. Institute of Health Sciences and Sports, Tallinn University, Räägu 49, Tallinn

E-mail: boris.baz@gmail.com

9th INSHS International Christmas Sport Scientific Conference, 4-6 December 2014. International Network of Sport and

Health Science. Szombathely, Hungary.

JOURNAL OF HUMAN SPORT \& EXERCISE ISSN 1988-5202

(c) Faculty of Education. University of Alicante

doi:10.14198/jhse.2015.10.Proc1.03 


\section{INTRODUCTION}

The jump shot is one of the most frequently used methods of shooting in the modern basketball. For example in the Spanish league, it accounts for $41 \%$ of all points (Rojas et al., 2000). Several studies have examined shooting technique at different distances from the basket (Bartlett and Miller, 1996; Okazaki and Rodacki, 2012). Rojas et.al. (2000) were analyzed the adjustments in technique made by a basketball player when shooting against an opponent. The authors suggested that training would benefit from practice with an opponent for at least some of the time to condition players to the demands which they were more likely to meet in the game situation. Okazaki et al. (2007) studied the relationship between speed and accuracy in basketball shoot. The results of the correlation analysis revealed small relationship $(r=0,22$; $p>0,05)$ between ball's release speed and shooting accuracy. Based on the results the authors believe that ball's release speed is not the main factor that affects the accuracy of shooting in basketball. Players were able to manipulate the other variables (such as release angle and height) to compensate release speed (Okazaki et. al., 2007).

In a more recent investigation Okazaki and Rodacki (2012) have analyzed the effect of increased distance on basketball jump shot outcome and performance. Ten male expert basketball players were filmed and a number of kinematic variables analyzed during jump shot that were performed from three conditions to represent close, intermediate and far distances $(2.8,4.6$, and $6.4 \mathrm{~m}$, respectively). They found, that shot accuracy decreased from $59 \%$ (close) to $37 \%$ (far), in function of the task constraints $(p<0.05$ ). Ball release height decreased $(p<0.05)$ from $2.46 \mathrm{~m}$ (close) to $2.38 \mathrm{~m}$ (intermediate) and to $2.33 \mathrm{~m}$ (long). Release angle also decreased $(p<0.05)$ when the shot was performed from close $\left(78.92^{\circ}\right)$ in comparison to intermediate distances $\left(65.60^{\circ}\right)$. While, ball release velocity increased $(p<0.05)$ from $4.39 \mathrm{~m} / \mathrm{s}$ (close) to $5.75 \mathrm{~m} \cdot \mathrm{s}-1$ (intermediate) to $6.89 \mathrm{~m} \cdot \mathrm{s}-1$ (far). Authors concluded that changes in ball release height, angle and velocity are the main factors that influence jump shot accuracy when distance is augmented (Okazaki \& Rodacki, 2012).

Based on the results of our previous research which enabled to determine the phase structure and create rhythm models of shooting in elite male basketball (Bazanov, 2001, 2014) the purpose of this study was to improve the shooting rhythm of jump shot performances of male under 20 years old basketball players.

\section{MATERIAL AND METHODS}

The task was carried out by using the methodology of kinematic analysis developed in the Centre for Kinesiology Studies of Tallinn University (Bazanov, 2001; Gross, 1991; Haljand, 1995).

Shooting activity is studied as a system of movements consisting of phases:

- Based on kinematic characteristics the whole action of shooting is divided into 5 phases and examined quantitatively and qualitatively .

- Each phase has a unique name and is determined by the clear moment of the beginning and the end (see table 1).

- Each phase has an own goal and technique requirements.

- One phase includes the movements of the whole body. 
Table 1. The names of phases and their limit moments

\begin{tabular}{ccccccc}
\hline The name & Catching & Sitting down & Jumping up & Shooting & \multicolumn{2}{c}{ Follow throw } \\
\hline $\begin{array}{c}\text { Limit } \\
\text { moment }\end{array}$ & $\begin{array}{c}\text { The first } \\
\text { touch of the } \\
\text { ball }\end{array}$ & $\begin{array}{c}\text { Beginning of } \\
\text { raising up the } \\
\text { ball }\end{array}$ & $\begin{array}{c}\text { The start of } \\
\text { legs } \\
\text { extention }\end{array}$ & $\begin{array}{c}\text { The Start of } \\
\text { elbow } \\
\text { extention }\end{array}$ & $\begin{array}{c}\text { The end of } \\
\text { wrist } \\
\text { bending }\end{array}$ & $\begin{array}{c}\text { The end of legs } \\
\text { amortisation }\end{array}$ \\
\hline
\end{tabular}

Sample and description of the process

Five male basketball players (18.2+/- 0.4 years old, experience $6.8 \pm 2.2$ years) performed before and after the feedback session $300(150+150)$ middle range $(6.0 \mathrm{~m})$ jump shots from three different positions (one directly in front of the basket and the other two on the wings). All the players ( 3 guards and 2 forwards) were right-handed. All the shots were made after receiving a pass that was given directly from the basket. One digital video camera was used at $60 \mathrm{~Hz}$ frame rate to record the performance of the shots. Shutter speed was $500 \mathrm{~Hz}$. It was placed in an orientation of $90^{\circ}$ in the direction of the shots. The duration of jump shot phases and the whole activity were measured by "Kinovea" program (0.8.15) and a qualitative evaluation protocol was filled. The protocol consists of 20 requirements, which are divided into five phases.

The feedback session lasted 45 minutes, during which the players were shown videos of their shots, directing attention to the positive and negative sides of shooting technique. In addition to the video feedback players have performed practical exercises (10 $\mathrm{min}$ for each player), that were aimed to improve the rhythm of the shoot.

\section{Statistical analysis}

The data obtained were inserted into the MS Excel 2007 program and analyzed using descriptive statistics. The reliability of the differences was examined by F-test and T-test. The shooting accuracy was calculated in percentages.

\section{RESULTS}

The main results are shown in the following table 2 . We can see, that duration of the whole jump shot activity reduced from $1.27 \mathrm{~s}(+/-S D 0.11)$ to $1.1 \mathrm{~s}(+/-S D$ 0.09) $(p<0.01)$. The main changes occurred in preparation ("catching" and "sitting down") phases.

Table 2. Comparison of jump shot rhythm before and after the feedback session

\begin{tabular}{|c|c|c|c|c|c|c|c|c|c|c|c|c|c|c|}
\hline \multirow{2}{*}{$\begin{array}{l}\text { Phases } \\
\text { Testing }\end{array}$} & \multicolumn{2}{|c|}{ Catching } & \multicolumn{2}{|c|}{ Sitting down } & \multicolumn{2}{|c|}{ Jumping up } & \multicolumn{2}{|c|}{ Shooting } & \multicolumn{2}{|c|}{ Follow throw } & \multicolumn{2}{|c|}{ 1-4 phases } & \multicolumn{2}{|c|}{$\begin{array}{c}\text { The whole } \\
\text { action }\end{array}$} \\
\hline & $\begin{array}{c}\text { Befor } \\
e\end{array}$ & $\begin{array}{c}\text { Afte } \\
r\end{array}$ & $\begin{array}{c}\text { Befor } \\
e\end{array}$ & $\begin{array}{c}\text { Afte } \\
r\end{array}$ & $\begin{array}{c}\text { Befor } \\
e\end{array}$ & $\begin{array}{c}\text { Afte } \\
r\end{array}$ & $\begin{array}{c}\text { Befor } \\
\text { e }\end{array}$ & $\begin{array}{c}\text { Afte } \\
r\end{array}$ & $\begin{array}{c}\text { Befor } \\
e\end{array}$ & $\begin{array}{c}\text { Afte } \\
r\end{array}$ & $\begin{array}{c}\text { Befor } \\
\text { e }\end{array}$ & $\begin{array}{c}\text { Afte } \\
r\end{array}$ & $\begin{array}{l}\text { Befor } \\
e\end{array}$ & $\begin{array}{c}\text { Afte } \\
r\end{array}$ \\
\hline MAX & 0.66 & 0.46 & 0.35 & 0.3 & 0.33 & 0.36 & 0.26 & 0.28 & 0.36 & 0.35 & 1.27 & 1.11 & 1.6 & 1.32 \\
\hline MIN & 0.16 & 0.11 & 0.13 & 0.06 & 0.15 & 0.15 & 0.13 & 0.13 & 0.18 & 0.15 & 0.75 & 0.57 & 1.07 & 0.87 \\
\hline $\begin{array}{c}\text { Averag } \\
\mathrm{e}\end{array}$ & 0.33 & 0.25 & 0.22 & 0.13 & 0.22 & 0.25 & 0.21 & 0.2 & 0.29 & 0.27 & 0.98 & 0.83 & 1.27 & 1.1 \\
\hline SD & 0.1 & 0.07 & 0.04 & 0.03 & 0.04 & 0.06 & 0.03 & 0.03 & 0.04 & 0.04 & 0.12 & 0.09 & 0.11 & 0.09 \\
\hline $\mathrm{F}-$ & \multicolumn{2}{|c|}{ 5.77E-06 } & \multicolumn{2}{|c|}{0.025840419} & \multicolumn{2}{|c|}{0.00204205} & \multicolumn{2}{|c|}{0.0872107} & \multicolumn{2}{|c|}{0.387576} & \multicolumn{2}{|c|}{0.000859278} & \multicolumn{2}{|c|}{0.00390857} \\
\hline T- & \multicolumn{2}{|c|}{$8.07 \mathrm{E}-15$} & \multicolumn{2}{|c|}{$4.79 \mathrm{E}-61$} & \multicolumn{2}{|c|}{ 8.62E-07 } & \multicolumn{2}{|c|}{$4,95 E-01$} & \multicolumn{2}{|c|}{0.000256} & \multicolumn{2}{|c|}{$5.25 \mathrm{E}-25$} & \multicolumn{2}{|c|}{$5.85 E-33$} \\
\hline
\end{tabular}




\section{DISCUSSION}

Our previous research enabled to determine the phase structure and variability of the movements and create a learning model of jump shot in elite male basketball (Bazanov, 2001, 2014). Based on the correlation analysis, we have found, that the closest relationship is between the duration of "Catching" phase and the whole activity $(r=0.79)$. Along with the duration of the "Catching" phase, the whole activity is closely related with the "Sitting down" phase $(r=0.47)$. The analysis of shooting variability showed, that the coefficient of variation of preparatory phases is higher than in the operating activities. Based on the results we concluded that setting a goal to reduce the length of jump shot basketball player should improve the activity of the "Catching" and "Sitting down" phases. The requirements developed in these studies have helped us to control, manage and correct mistakes in the technical preparation of basketball players. The aim of the current study was to improve the shooting rhythm of jump shot performances of male under 20 years old basketball players.

Quantitative analysis of the pre-test results showed a significant deviation from the optimal execution time of the "Catching" $(0.33+/-0.10)$ and "Sitting down" $(0.22+/-0.04)$ phases. Video analysis of shooting performances allowed us to identify the possible causes of deviations.

In order to improve the performance of shooting basketball, during the feedback session and practical exercises we suggested players start activity with a low "take-off" jump and catch the ball being in the air. As an essential requirement of the "Catching" phase was to use "jump stop" technique.

After the feedback session and practical exercises, second test was performed.

Comparison of the pre-test and post-test results showed a significant change in the duration of the shooting technique. The duration of the "Catching" and "Sitting down" phases decreased respectively from $0.33+/-$ $0.10 \mathrm{Sec}$ to $0.25+/-0.07 \mathrm{Sec}$ and $0.22+/-0.04$ to $0.13+/-0.03 \mathrm{Sec}$ on average $(p<0.01)$. In our previous study (Bazanov, 2001) we found, that at the high level of male basketball performance with the decrease of duration of "Sitting down" phase slightly decrease the shooting arc $(r=0.31)$. This may be one reason why the shooting accuracy decreased from $40 \%$ to $30 \%$. On the other hand, players had too little time to adapt to the modified structure of the shot. We can assume, that the faster shot meets the conditions of competitive game and therefore in training sessions it is needed to perform the shots according to the real game environment, paying attention to the proper form of technique. We agree with the position of Rojas et al (2000) occasionally to perform jump shots with an opponent.

\section{CONCLUSIONS}

The results of this study indicate, that the major deviations from the optimum rhythm of shooting basketball occurred in the preparatory phases. Objective feedback and simple exercises optimized the duration of shooting activity and modified the usual jump shot technique, accompanied by a slight decrease in shooting accuracy.

\section{REFERENCES}

1. Bazanov, B. (2001). Structural analysis and optimization of jump shot technique in basketball. (Master thesis). Tallinn University. 
2. Bazanov, B. (2014). How to reduce the duration of jump shot in basketball? Fundamental and applied kinesiology-steps forward. Proceedings of 7 th international scientific conference on kinesiology (pp.428).

3. Gross, H. (1991). Pedagoogilise Kinesioloogia Kujunemine ja Areng Eestis. Tallinn University.

4. Haljand, R. (1995). Technical analysis and kinesiological teaching, a part of modern coaching. The Way to Win. Liikuntatiedellisen Seuran julkaisu, 141, pp.111-113.

5. Miller, S., \& Bartlett, R.M. (1996). The relationship between basketball shooting kinematics, distance and playing position. Journal of Sports Sciences, 14, pp.243 - 253.

6. Okazaki, V.H.A., Okazaki, F.H.A., Sasaki, J.E., \& Keller, B. (2007). Speed-accuracy relationship in basketball shoot. The Fiep Bulletin, 77, pp.745-747.

7. Okazaki, V.H.A., \& Rodacki, A.L.F. (2012). Increased distance of shooting on a basketball jump shot. Journal of Sports Science and Medicine, 11, pp.231-237.

8. Rojas, F.J., Cepero, M., Ona, A., \& Gutierrez, M. (2000). Kinematic Adjustments in the Basketball Jump Shot Against an Opponent. Ergonomics, 43, pp.1651-1660. 